\title{
Complications after Radiofrequency Ablation for Hepatocellular Carcinoma: A Multicenter Study Involving 9,411 Japanese Patients
}

\author{
Masaki Maedaa Issei Saekia Isao Sakaida ${ }^{a} \quad$ Hiroshi Aikata ${ }^{c}$ Yasuyuki Araki ${ }^{d}$
}

Chikara Ogawa $^{e}$ Kazuya Kariyama ${ }^{f}$ Kazuhiro Nouso $^{f}$ Mikiya Kitamoto $^{g}$

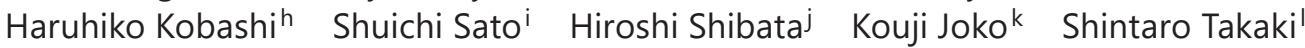

Hiroyuki Takabatake $^{m} \quad$ Akemi Tsutsui $^{\text {n }}$ Koichi Takaguchi $^{n}$ Tetsu Tomonari ${ }^{\circ}$

Shinichiro Nakamura ${ }^{p}$ Takakazu Nagahara ${ }^{q}$ Atsushi Hiraokar ${ }^{r}$ Tomomitsu Matono $^{s}$

Masahiko Kodat ${ }^{t}$ Mari Mandai ${ }^{u}$ Tomohiko Mannamiv,w Akeri Mitsudax

Takashi Moriyay Kazuhisa Yabushita ${ }^{\mathrm{z}}$ Joji Tani ${ }^{\mathrm{A}}$ Takahito Yagi ${ }^{\mathrm{B}}$ Takahiro Yamasaki ${ }^{\mathrm{a}, \mathrm{b}}$

a Department of Gastroenterology and Hepatology, Yamaguchi University Graduate School of Medicine, Yamaguchi, Japan; ${ }^{b}$ Department of Oncology and Laboratory, Yamaguchi University Graduate School of Medicine, Yamaguchi, Japan; ' Department of Gastroenterology and Metabolism, Applied Life Sciences, Institute of Biomedical and Health Science, Hiroshima University, Hiroshima, Japan; ${ }^{\mathrm{d}}$ Division of Internal Medicine, Hiroshima City Hiroshima Citizens Hospital, Hiroshima, Japan; e Division of Gastroenterology and Hepatology, Takamatsu Red Cross Hospital, Kagawa, Japan;

fDivision of Gastroenterology and Hepatology, Okayama City Hospital, Okayama, Japan; 9 Department of Gastroenterology, Hiroshima Prefectural Hospital, Hiroshima, Japan; hivision of Gastroenterology and Hepatology, Japanese Red Cross Okayama Hospital, Okayama, Japan; 'Department of Hepatology, Shimane University Hospital, Shimane, Japan; 'Division of Gastroenterology and Hepatology, Tokushima Prefectural Central Hospital, Tokushima, Japan; ${ }^{k}$ Division of Gastroenterology and Hepatology, Matsuyama Red Cross Hospital, Ehime, Japan; 'Division of Gastroenterology and Hepatology, Hiroshima Red Cross and Atomic Bomb Survivors Hospital, Hiroshima, Japan; mDivision of Gastroenterology and Hepatology, Kurashiki Central Hospital, Okayama, Japan; ${ }^{n}$ Department of Hepatology, Kagawa Prefectural Central Hospital, Kagawa, Japan; ${ }^{\circ}$ Department of Gastroenterology and Hepatology, Tokushima University Graduate School, Tokushima, Japan; PDepartment of Gastroenterology and Hepatology, Okayama University Hospital, Okayama, Japan; qDivision of Gastroenterology and Hepatology, Tottori Prefectural Kousei Hospital, Tottori, Japan; 'Gastroenterology Center, Ehime Prefectural Central Hospital, Ehime, Japan; ${ }^{5}$ Division of Medicine and Clinical Science, Department of Multidisciplinary Internal Medicine, Tottori University Faculty of Medicine, Tottori, Japan; ${ }^{\mathrm{t} D e p a r t m e n t}$ of Internal Medicine, Hino Hospital, Tottori, Japan; u'Division of Internal Medicine, Okayama Saiseikai General Hospital, Okayama, Japan; " Division of Gastroenterology and Hepatology, Chugoku Central Hospital, Hiroshima, Japan; wDepartment of Gastroenterology, National Hospital Organization Okayama Medical Center, Okayama, Japan; ${ }^{x}$ Division of Gastroenterology and Hepatology, Tottori Red Cross Hospital, Tottori, Japan; ' ${ }^{\text {Division }}$ of Gastroenterology and Hepatology, Chugoku Rousai Hospital, Hiroshima, Japan; ${ }^{2}$ Division of Internal Medicine, Fukuyama City Hospital, Hiroshima, Japan; A Department of Gastroenterology and Neurology, Kagawa University Faculty of Medicine, Kagawa, Japan; ${ }^{B}$ Department of Gastroenterological Surgery Transplant and Surgical Oncology, Okayama University Graduate School of Medicine, Dentistry and Pharmaceutical Sciences, Okayama, Japan 


\title{
Liver Cancer
}

\begin{tabular}{|c|c|}
\hline Liver Cancer 2020;9:50-62 & \\
\hline DOI: $10.1159 / 000502744$ & $\begin{array}{l}\text { (c) } 2019 \text { The Author(s). Published by S. Karger AG, Basel } \\
\text { www.karger.com/lic }\end{array}$ \\
\hline
\end{tabular}

Maeda et al.: Complications after RFA for HCC

\section{Keywords}

Complication $\cdot$ Hepatocellular carcinoma $\cdot$ Mortality $\cdot$ Radiofrequency ablation

\begin{abstract}
Introduction: Radiofrequency ablation (RFA) for hepatocellular carcinoma (HCC) is considered a safe and minimally invasive procedure. We previously reported that the mortality and complication rates for RFA were $0.038 \%$ (5/13,283 patients) and 3.54\% (579 complications/16,346 procedures), respectively, from 1999 to 2010 (previous period). In this study, we investigated the clinical criteria for RFA and the mortality and complication rates from 2011 to 2015 (recent period). Methods: Data were collected from 25 centers by using a questionnaire developed by the Chugoku-Shikoku Society for Local Ablation Therapy of HCC. The criteria for RFA, RFA modification, use of image-guidance modalities, mortality, and complications during the previous and recent periods were compared. Results: We evaluated 11,298 procedures for 9,411 patients, including those that involved new devices (bipolar RFA and internally adjustable electrode system). The criterion of hepatic function for RFA increased from a Child-Pugh score $\leq 8$ during the previous period to $\leq 9$ during the recent period. The criteria regarding the tumor location and other risk factors have been expanded recently because of the increased use of several modifications of the RFA procedure and image-guidance modalities. The mortality rate was $0.064 \%$ (6/9,411 patients), and the complication rate was $2.92 \%$ (330 complications/11,298 procedures). There was no difference in mortality rates between the 2 periods ( $p=0.38$ ), but the complication rates was significantly lower during the recent period ( $p=0.038$ ). Discussion and Conclusions: Our findings confirmed that RFA, including the use of new devices, is a low-risk procedure for HCC, despite the expansion of the criteria for RFA during the recent period.

(c) 2019 The Author(s)

Published by S. Karger AG, Basel
\end{abstract}

\section{Introduction}

Hepatocellular carcinoma (HCC) is the sixth most common cancer and the fourth leading cause of cancer-related deaths worldwide [1]. In Japan, more than $60 \%$ of HCC cases are diagnosed at an early stage (Barcelona Clinic Liver Cancer stage 0 or A), which can be treated with curative therapies such as surgical resection, local ablation, and liver transplantation [2]. According to a nationwide survey of primary cancer in Japan, local ablation provides a viable alternative to surgical resection and is the first treatment choice for $29.3 \%$ of HCC cases, with the majority treated with radiofrequency ablation (RFA) [3].

RFA was first used in Japan in 1999. By 2000, almost all institutions in Japan were performing the procedure. Although RFA is considered a safe and minimally invasive procedure, several complications have been reported [4-14]. We previously reported mortality and complication rates of 0.038 and 3.54\%, respectively, across 20 centers in Japan between January 1999 and October 2010 [15]. Based on these data, we confirmed that RFA may be considered a safe and mostly well-tolerated treatment for HCC.

Recently, a novel bipolar RFA system $[16,17]$ and an internally cooled adjustable electrode system [18] have been introduced in Japan; however, there have been no reports, to date, regarding the complication rates associated with these devices in a large population. Additionally, recent modalities, such as artificial ascites, artificial pleural effusion, contrastenhanced ultrasound (CE-US), and multimodality fusion imaging, have been developed [19]. These imaging modalities could improve the effectiveness of RFA for the treatment of small HCC lesions, which are usually inconspicuous on ordinary ultrasound imaging. These advances in RFA and imaging techniques could expand the therapeutic indications for RFA. Therefore, 
we aimed to investigate the criteria for RFA and the mortality and complication rates associated with RFA including the use of new devices during a 5-year period (from 2011 to 2015) across 25 centers. Furthermore, we compared data obtained during this recent period (2011$2015)$ to the data obtained during a previous period of observation (1999-2010) that were previously reported [15].

\section{Methods}

In July 2016, a questionnaire developed by the Chugoku-Shikoku Society for the Local Ablation Therapy of HCC was sent to 37 centers in the Chugoku and Shikoku regions of Japan. These centers were affiliated with the Chugoku Shikoku Society for the Local Ablation Therapy of HCC and included all major hospitals where RFA was performed routinely in the Chugoku and Shikoku regions. Replies to this questionnaire were obtained from 25 centers (response rate, 67.6\%). The questionnaire was based on a previous report [15] and included the following items: (1) background factors used as an indication for RFA (cutoff of the blood platelet count used to determine the need for transfusion or oral thrombopoietin receptor agonist therapy; cutoff of the total bilirubin level; cutoff of the prothrombin time; presence of ascites; and cutoff of the ChildPugh score); (2) RFA indications for tumor location or other factors that increase the risk for complications (position adjacent to the first or second branch of the portal vein or bile duct, origin of the hepatic veins or inferior vena cava or adjacent to the gallbladder, and the presence of a bilioenteric anastomosis or papillary dysfunction); (3) tumor characteristics considered for RFA, including tumor size and number of tumors; (4) modifications to the RFA procedure, including the use of artificial ascites, artificial pleural effusion, and bile duct cooling; (5) total number of RFA procedures performed between January 2011 and December 2015, as an indicator of the RFA expertise at a center as well as the device used for RFA; (6) number of RFA procedures performed using image-guidance modalities (CE-US, multimodality fusion imaging such as Real-time Virtual Sonography [Hitachi, Ltd, Tokyo, Japan], Smart Fusion [Canon Medical Systems, Tokyo, Japan], and Volume Navigation [GE Healthcare, Tokyo, Japan], three-dimensional [3D] sim-Navigator [3D-SIM; Hitachi, Ltd], and computed tomography [CT] guidance); and (7) mortality and complication rates associated with RFA procedures during an observation period of at least 1 month after RFA. Major complications were assessed according to the guidelines of the Society of Interventional Radiology [20,21]. Data gathered during the recent period (2011-2015) were compared to our previous data collected from 1999 to 2010 across 20 centers, including differences in mortality and complication rates [15].

Our study methods were approved by the Institutional Review Board (IRB) of Yamaguchi University Hospital (Ube, Japan, H29-071) and by the IRB of the other 8 centers not directly affiliated with Yamaguchi University Hospital. Because of the retrospective nature of our study, consent from individual patients was not required.

\section{Statistical Analysis}

Data were expressed as the mean \pm SD. Between-group differences were evaluated using a chi-square test or Student $t$ test as appropriate for the type of data variable. Statistical significance was defined as $p<$ 0.05. All analyses were performed using the JMP 13.0 software package (SAS Institute, Inc., Cary, NC, USA).

\section{Results}

\section{Criteria for RFA}

We analyzed the criteria used to define hepatic function as an indication for RFA during the previous period and the recent period (Fig. 1). The criteria during the previous period were as follows: total bilirubin $\leq 3 \mathrm{mg} / \mathrm{dL}$ at $14(70 \%)$ of 20 centers; prothrombin time $\geq 50 \%$ at $11(55 \%)$ centers; platelet count $\geq 5 \times 10^{4} / \mathrm{mm}^{3}$ at $10(50 \%)$ centers; absence of ascites after medication at $15(50 \%)$ centers; and a Child-Pugh score $\leq 8$ at 7 (35\%) centers. During the recent period, the hepatic function criteria for RFA indications were as follows: total bilirubin $\leq 3 \mathrm{mg} / \mathrm{dL}$ at $20(80 \%)$ of 25 centers; prothrombin time $\geq 50 \%$ at $13(52 \%)$ centers; 


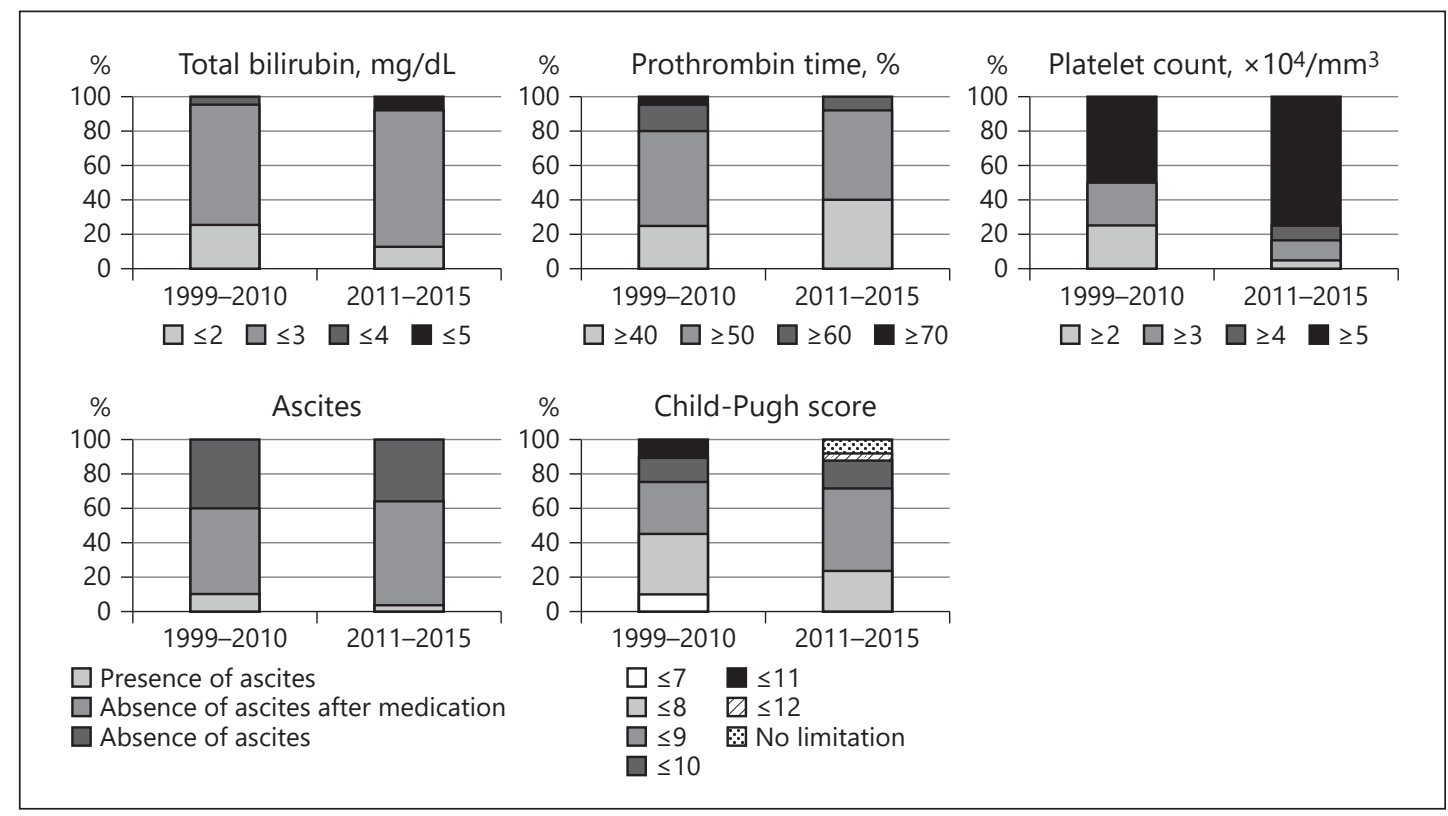

Fig. 1. Hepatic function criteria for RFA during the previous (1999-2010, 20 centers) and recent periods (2011-2015, 25 centers). The criteria used during the previous period were as follows: total bilirubin $\leq 3 \mathrm{mg} / \mathrm{dL}$ at $14(70 \%)$ of 20 centers; prothrombin time $\geq 50 \%$ at $11(55 \%)$; platelet count $\geq 5 \times 10^{4} / \mathrm{mm}^{3}$ at 10 (50\%); absence of ascites after medication at 15 (50\%); and Child-Pugh score $\leq 8$ at 7 (35\%). During the recent period, the hepatic function criteria for RFA were as follows: total bilirubin $\leq 3 \mathrm{mg} / \mathrm{dL}$ at $20(80 \%)$ of 25 centers; prothrombin time $\geq 50 \%$ at 13 (52\%); platelet count $\geq 5 \times 10^{4} / \mathrm{mm}^{3}$ at $19(76 \%)$; absence of ascites after medication at 15 (60\%); and Child-Pugh score $\leq 9$ at $12(48 \%)$.

platelet count $\geq 5 \times 10^{4} / \mathrm{mm}^{3}$ at $19(76 \%)$ centers; absence of ascites after medication at 15 (60\%) centers; and Child-Pugh score $\leq 9$ at $12(48 \%)$ centers.

Figure 2 shows the tumor location or other factors associated with a higher risk of mortality and complications for RFA. The following differences were identified between the previous and recent periods. During the previous period, patients with risk I had HCC adjacent to the first or second branch of the portal vein or bile duct were considered to be RFA candidates at 15 of 20 centers (75\%); those with risk II had HCC adjacent to the origin of the hepatic veins or the inferior vena cava at 18 centers (90\%); those with risk III had HCC adjacent to the gallbladder at 13 centers (65\%); and those with risk IV had a bilioenteric anastomosis or papillary dysfunction at 5 centers (25\%). During the recent period, patients with risk I, risk II, risk III, and risk IV were considered RFA candidates at 21 of 25 centers (84\%), 25 centers (100\%), 16 centers (64\%), and 10 centers (40\%), respectively.

Additionally, in this study, we included the number of tumors and the maximum tumor size in the criteria for RFA. Regarding the number of tumors, $\leq 3$ tumors was the cutoff used at $13(52 \%)$ centers, $\leq 5$ was used at $4(16 \%)$ centers, $\leq 6$ was used at $1(4 \%)$ center, and $\leq 10$ was used at $1(4 \%)$ center; there was no limitation at $6(24 \%)$ centers. The maximum tumor size was $\leq 3 \mathrm{~cm}$ at 17 centers $(68 \%), \leq 4 \mathrm{~cm}$ at $2(8 \%)$ centers, $\leq 5 \mathrm{~cm}$ at $4(16 \%)$ centers, and $\leq 10 \mathrm{~cm}$ at $1(4 \%)$ center; there was no limitation at $1(4 \%)$ center. Thirteen centers $(52 \%)$ used the general criteria of $\leq 3 \mathrm{HCC}$ lesions with a diameter $\leq 3 \mathrm{~cm}$ as indications for RFA.

\section{Modifications of the RFA Procedure}

Several modifications to the RFA procedure have been developed for the treatment of HCC lesions in high-risk locations. During the previous period, these included the use of artificial 


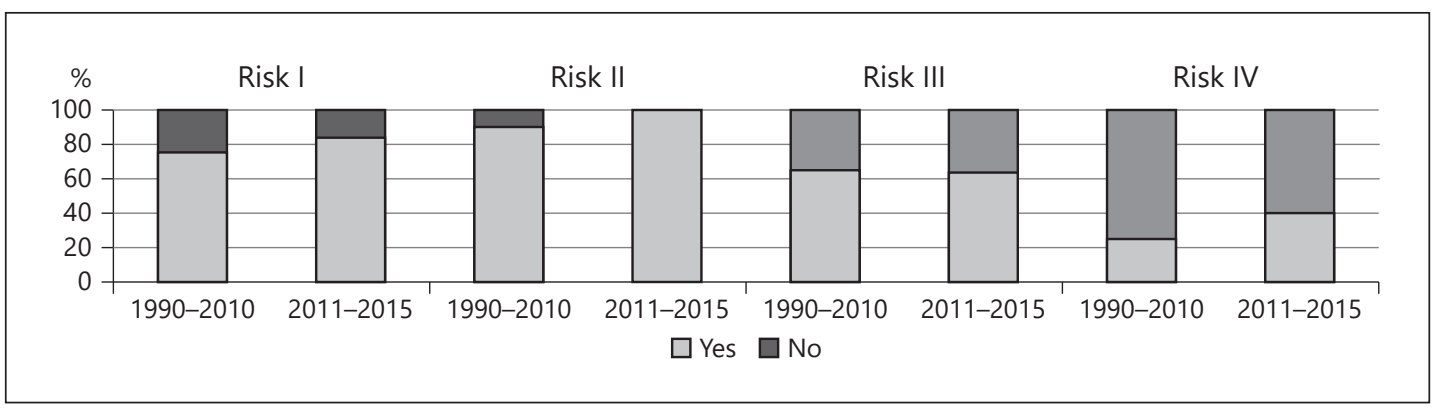

Fig. 2. Criteria regarding tumor location or other factors associated with a higher risk of mortality and complications with RFA of the previous (1999-2010, 20 centers) and the recent (2011-2015, 25 centers) periods. During the previous period, patients with risk I (HCC adjacent to the first or second branch of the portal vein or bile duct) were considered to be RFA candidates at 15 of 20 centers (75\%). Those with risk II (HCC adjacent to the origin of the hepatic veins or the inferior vena cava) were candidates at 18 centers (90\%). Those with risk III (HCC adjacent to the gallbladder) were candidates at 13 centers (65\%). Those with risk IV (a bilioenteric anastomosis or papillary dysfunction) were candidates at 5 centers (25\%). During the recent period, patients with risk I, risk II, risk III, and risk IV were considered RFA candidates at 21 of 25 centers $(84 \%), 25$ centers $(100 \%), 16$ centers $(64 \%)$, and 10 centers $(40 \%)$, respectively.

ascites at 17 (85\%) centers, artificial pleural effusion at 15 (75\%) centers, and bile duct cooling using a nasobiliary drainage tube at $5(25 \%)$ centers. During the recent period, these same modifications were performed at 23 (92\%), 24 (96\%), and 8 centers (32\%), respectively (Fig. 3).

\section{Patients and RFA Procedures}

We evaluated 11,298 RFA procedures performed for 9,411 patients treated across 25 centers. Of these 11,298 procedures, RFA monotherapy was performed for 6,874 (60.8\%) patients and RFA in combination with transcatheter arterial chemoembolization or lipiodoltranscatheter arterial infusion chemotherapy was performed for 4,424 (39.2\%) patients. The mean number of RFA procedures per year was $90.3 \pm 75$.1. Twenty-one of the 25 participating centers $(84 \%)$ performed $\geq 101$ RFA procedures during the 5 years of the recent period of observation, and 11 centers (44\%) performed $\geq 501$ RFA procedures during this same 5 -year period. Expert physicians (median 3 physicians; range 1-8) performed RFA. Twenty-one centers had at least one physician with 10 years or more of experience with percutaneous ablation therapies at the beginning of this study, and 4 centers had at least one physician with 5 years or more of experience. In addition, 14 of the 25 participating centers also participated in the previous study [15], and 11 of 14 centers had at least one physician with 10 years or more of experience at the beginning of this study. After the RFA procedure, antibiotic agents were administered for a few days (median 3 days; range 1-5) at 19 centers (76\%), and 6 centers (24\%) did not use an antibiotic agent.

In terms of the devices used for RFA, the Cool-tip Radiofrequency System (Convidien, Boulder, CO, USA) was used at all 25 centers. In addition, the RTC System (Boston Scientific Japan Co., Tokyo, Japan) was used at 8 centers, and the RITA RFA System (RITA MEDICAL SYSTEM, Fremont, CA, USA) was used at 2 centers. The Celon-POWER System (Olympus Winter and Ibe, GmbH, Telto, Germany) and VIVARF System (STARmed Co., Korea), which are new RFA devices, were used at 13 and 11 centers, respectively.

The annual trend for the type of RFA procedure performed during the recent 5-year period of observation is shown in Figure 4. There was an overall decrease in the annual number of RFA procedures performed during the observation period. Of the total number of procedures performed $(11,298$ procedures), 9,935 (87.94\%) were performed using the 


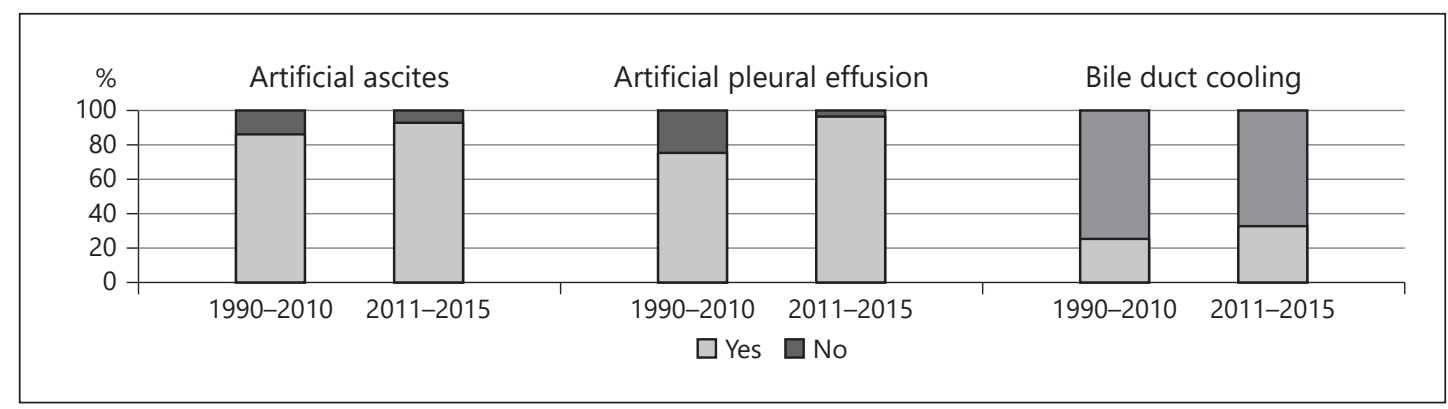

Fig. 3. Several modifications of the RFA procedure during the previous (1999-2010, 20 centers) and recent (2011-2015, 25 centers) periods. During the previous period, procedures included the use of artificial ascites at 17 centers (85\%), artificial pleural effusion at $15(75 \%)$, and bile duct cooling using a nasobiliary drainage tube at 5 (25\%); during the recent period, these same modifications were performed at 23 (92\%), 24 (96\%), and 8 centers (32\%), respectively.

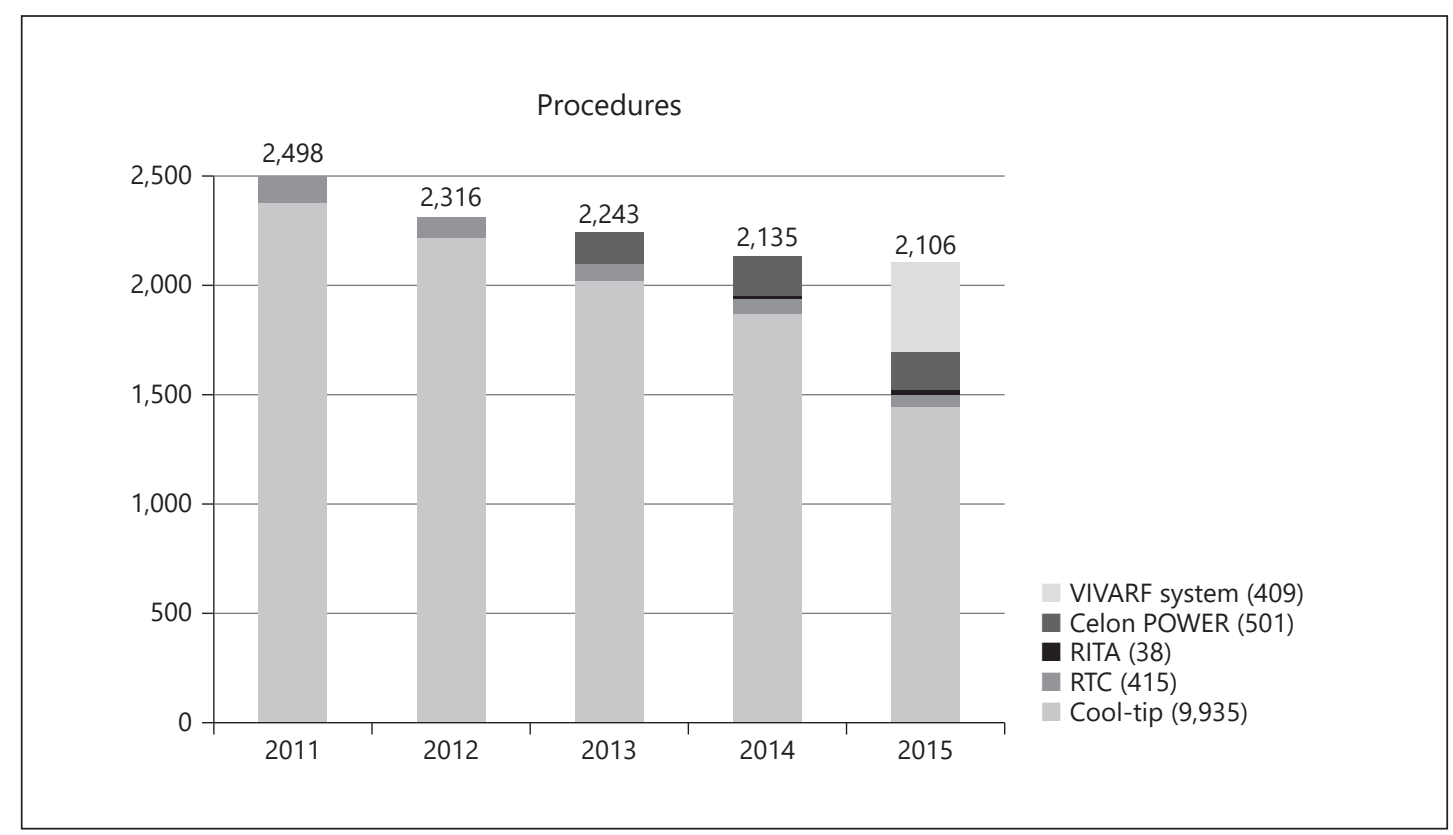

Fig. 4. Annual trend of the use of RFA during the 5-year period from 2011 to 2015 showing a gradual decline in the number of RFA procedures performed. Of the total number of RFA procedures performed, 87.94\% (9,935 procedures) were performed using the Cool-tip Radiofrequency System, 3.67\% (415 procedures) were performed using the RTC System, $0.34 \%$ (38 procedures) were performed using the RITA RFA System, $4.43 \%$ (501 procedures) were performed using the Celon-POWER System, and 3.62\% (409 procedures) were performed using the VIVARF System.

Cool-tip Radiofrequency System, 415 (3.67\%) were performed using the RTC System, 38 $(0.34 \%)$ were performed using the RITA RFA System, 501 (4.43\%) were performed using the Celon-POWER System, which was introduced in 2013, and 409 (3.62\%) were performed using the VIVARF System, which was introduced in 2014. Interestingly, the proportion of RFA procedures using the Cool-tip Radiofrequency System was $94.9 \%(2,268 / 2,390$ procedures) in 2011; this proportion significantly $(p<0.001)$ decreased to $67.7 \%(1,367 / 2,018$ procedures) in 2015. During the previous period of observation (1999-2010), 16,346 procedures were performed for 13,283 patients across the 20 enrolled centers [15]. 


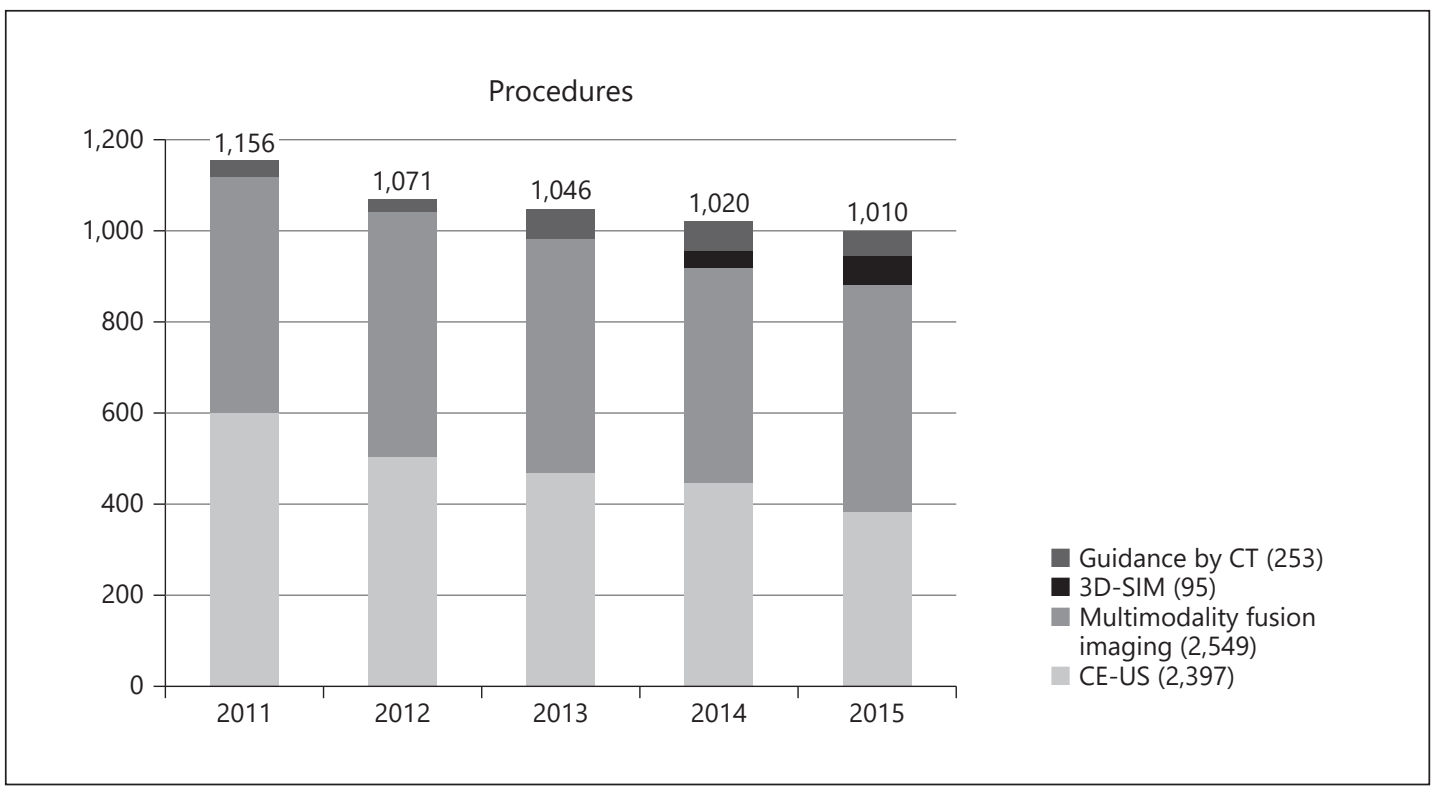

Fig. 5. Image-guidance modalities were used for almost half of all RFA procedures (5,294/11,298 procedures; 46.8\%). Of 5,294 procedures, 2,397 (45.3\%) used CE-US, 2,549 (48.1\%) used multimodality fusion imaging, 95 (1.8\%) used 3D-SIM, and 253 (4.8\%) used CT guidance. CE-US, contrast-enhanced ultrasound; 3D-SIM, 3-dimensional sim-Navigator; CT, computed tomography.

\section{Image-Guidance Modalities of the RFA Procedure}

Image-guidance modalities were used for almost half of the RFA procedures $(5,294$ of 11,298 procedures; $46.9 \%$ ) during the recent period; CE-US was used for 2,397 procedures (45.3\%), multimodality fusion imaging was used for 2,549 (48.1\%), 3D-SIM was used for 95 (1.8\%), and CT guidance was used for 253 (4.8\%; Fig. 5). The frequency of using imageguidance modalities increased slightly during the 5-year period as follows: $2011,46.3 \%$; $2012,46.2 \% ; 2013,46.6 \% ; 2014,47.8 \%$; and 2015, 47.9\%. Image-guidance modalities were used at 23 of the 25 centers with the following distribution: CE-US at 21 (84\%) centers; multimodality fusion imaging at 19 (76\%); 3D-SIM at 3 (12\%); and CT guidance at $13(52 \%)$.

\section{Complications and Mortality Associated with RFA}

Among the 11,298 procedures performed, 330 complications (2.92\%) were identified. Six patients $(6 / 9,411$ patients; $0.064 \%)$ died from RFA-related complications during the recent period (one each from intraperitoneal hemorrhage, refractory ascites, perforation of the intestine, bile duct injury, diaphragm injury, and refractory pleural effusion). All centers were classified into 2 groups: high-volume centers ( $\geq 501$ RFA procedures during 5 years) and low-volume centers ( $<501$ RFA procedures during 5 years). Eleven (44\%) and 14 (56\%) centers were high-volume and low-volume centers, respectively. There was no significant difference in the complication rates between the high-volume $(2.83 \pm 2.14 \%)$ and low-volume $(3.24 \pm 13.6 \%)$ centers $(p=0.30)$. During the previous period, the complication and mortality rates were $3.54 \%$ (579/16,346 procedures) and $0.038 \%$ (5/13,283 patients), respectively. Therefore, although there was no significant difference in the mortality rates of the recent and previous periods $(p=0.38)$, the complication rate was significantly lower during the recent period than during the previous period ( $p=0.038)$.

Table 1 shows the types of RFA-associated complications that were classified into the following 6 categories for analysis: hemorrhage, hepatic injuries, extrahepatic organ in- 
Table 1. Complications of radiofrequency ablation

\begin{tabular}{|c|c|c|c|c|c|}
\hline \multirow[t]{2}{*}{ Complications } & \multicolumn{2}{|c|}{ 1999-2010 } & \multicolumn{2}{|c|}{$2011-2015$} & \multirow[t]{2}{*}{$p$ value } \\
\hline & cases & $\%$ & cases & $\%$ & \\
\hline Hemorrhage & 78 & 0.477 & 63 & 0.558 & 0.800 \\
\hline Intraperitoneal hemorrhage & 32 & 0.196 & 17 & 0.150 & 0.467 \\
\hline Hemothorax & 25 & 0.153 & 26 & 0.230 & 0.155 \\
\hline Hemobilia & 13 & 0.08 & 12 & 0.106 & 0.468 \\
\hline Others & 8 & 0.049 & 8 & 0.071 & 0.458 \\
\hline Hepatic injuries & 319 & 1.952 & 148 & 1.310 & 0.040 \\
\hline Liver infarction & 75 & 0.459 & 34 & 0.301 & 0.041 \\
\hline Liver abscess & 32 & 0.196 & 12 & 0.106 & 0.090 \\
\hline Bile duct injury & 110 & 0.673 & 14 & 0.124 & $<0.001$ \\
\hline Biloma & 37 & 0.226 & 16 & 0.142 & 0.125 \\
\hline Portal thrombosis & 32 & 0.196 & 35 & 0.310 & 0.062 \\
\hline Refractory ascites & 29 & 0.177 & 31 & 0.274 & 0.114 \\
\hline Hepatic failure & 4 & 0.025 & 6 & 0.053 & 0.335 \\
\hline Extrahepatic organ injuries & 113 & 0.691 & 84 & 0.743 & 0.352 \\
\hline Heart & 2 & 0.012 & 0 & 0 & 0517 \\
\hline Lung & 9 & 0.055 & 48 & 0.424 & $<0.001$ \\
\hline Gastrointestinal & 9 & 0.055 & 5 & 0.044 & 0.791 \\
\hline Stomach & 3 & 0.018 & 0 & 0 & 0.275 \\
\hline Duodenum & 2 & 0.012 & 0 & 0 & 0.517 \\
\hline Colon & 1 & 0.006 & 2 & 0.018 & 0.571 \\
\hline Others & 3 & 0.018 & 0 & 0 & 0.275 \\
\hline Unknown & 0 & 0 & 3 & 0.027 & 0.068 \\
\hline Gallbladder & 5 & 0.031 & 0 & 0 & 0.084 \\
\hline Diaphragm & 8 & 0.049 & 2 & 0.018 & 0.215 \\
\hline Refractory pleural effusion & 43 & 0.263 & 27 & 0.239 & 0.717 \\
\hline Skin & 32 & 0.196 & 1 & 0.009 & $<0.001$ \\
\hline Others & 5 & 0.031 & 1 & 0.009 & 0.411 \\
\hline Tumor progression & 27 & 0.170 & 8 & 0.071 & 0.006 \\
\hline Needle tract seeding & 7 & 0.043 & 2 & 0.018 & 0.325 \\
\hline Intraperitoneal dissemination & 8 & 0.049 & 5 & 0.044 & 1.000 \\
\hline Rapid progression & 12 & 0.073 & 1 & 0.009 & 0.020 \\
\hline \multicolumn{6}{|c|}{ Skin burn due to poor contact between } \\
\hline the electrode pad and skin & 14 & 0.086 & 2 & 0.018 & 0.010 \\
\hline Others & 28 & 0.171 & 25 & 0.221 & 0.402 \\
\hline Total & 579 & 3.542 & 330 & 2.921 & 0.038 \\
\hline
\end{tabular}

juries, tumor progression, skin burn due to poor contact between the electrode pad and the skin, and others [15]. Hemorrhage was defined as a reduction of $>3 \mathrm{~g} / \mathrm{dL}$ in the hemoglobin concentration or requiring a blood transfusion, as reported in the previous study [15]. There were no significant differences in 2 categories (hemorrhage and extrahepatic organ injuries) between the 2 periods. For the category of extrahepatic organ injuries, 48 cases $(0.424 \%)$ of pneumothorax were reported, and the complication rate was markedly higher during the recent period than during the previous period ( 9 cases; $0.055 \%$ ); 19 patients required chest tube drainage as treatment. There were no injuries to the heart, stomach, duodenum, or gallbladder, and only 1 case of injury to the skin was identified $(0.009 \%)$. The complication rate during the recent period was markedly lower than that during the previous period (32 cases; 0.196\%). Specifically, the complication rates of the following 3 categories were significantly lower during the recent period than during the 


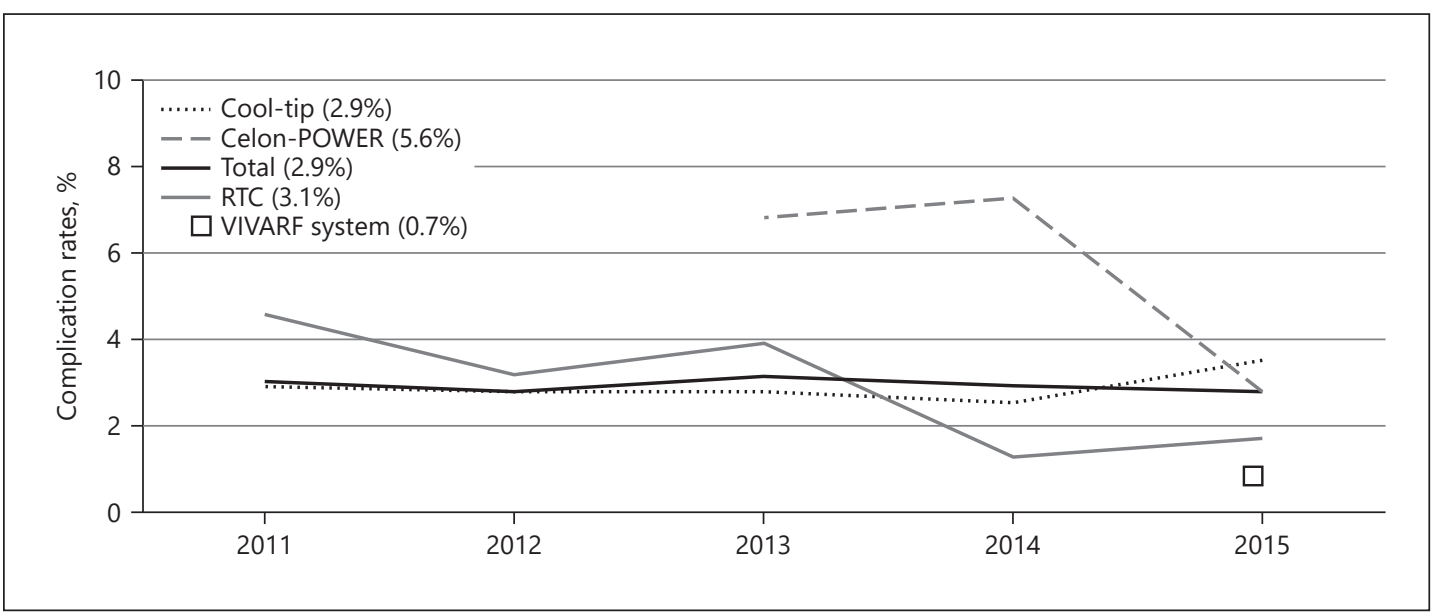

Fig. 6. Annual complication rates for different RFA systems. The complication rates were lowest for the Cooltip and RTC systems, at approximately 3\% each. However, the complication rate was high for the CelonPOWER System during the first 2 years (6.76\% in 2013 and $7.30 \%$ in 2014), but it decreased sharply in 2015 (2.86\%). The complication rates for the VIVARF System and the RITA System were $0.73 \%$ and $0 \%$ in 2015, respectively.

previous period: hepatic injuries, with the incidence of injury to the bile ducts during the recent period ( 14 cases; $0.124 \%$ ) being markedly lower than that during the previous period (110 cases; $0.673 \%$ ); tumor progression; and skin burn due to poor contact between the electrode pad and the skin.

\section{Annual Complication Rate for Different RFA Systems}

Figure 6 shows the annual complication rates for the different RFA systems used. The complication rates were lowest for the Cool-tip and RTC Systems, at approximately 3\% each. The complication rates were highest for the Celon-POWER System, at $6.76 \%$ in 2013 and $7.30 \%$ in 2014 ; however, the rate subsequently decreased to $2.86 \%$ in 2015 . The complication rates for the VIVARF System and the RITA System were 0.73 and $0 \%$ in 2015, respectively. The complication rates across the 6 categories (hemorrhage, hepatic injuries, extrahepatic organ injuries, tumor progression, and skin burn), specifically for the Cool-tip System and the Celon-POWER System, are shown in the online supplementary Table (for all online suppl. material, see www.karger.com/doi/10.1159/000502744). In the extrahepatic injuries category, the complication rate was significantly higher for the Celon-POWER System than for the Cool-tip System.

\section{Discussion and Conclusions}

RFA is currently considered the standard local-regional treatment for HCC worldwide for patients with $\leq 3$ tumors that are $\leq 3 \mathrm{~cm}$ in diameter [20,22-24], and it is considered a safe technique overall $[12,14]$. We previously reported the indications and complication rates for RFA across 20 centers between January 1999 and October 2010 [15]. However, recent advances in RFA equipment and techniques [16-18], as well as in RFA image-guidance modalities [19], have resulted in an expansion of the indications for RFA. Therefore, in this study, we compared the indications for RFA as well as the complication and RFA-associated death rates between the 2 periods. 


\section{Liver Cancer}

Maeda et al.: Complications after RFA for HCC

In the current study, the hepatic function criteria for RFA during the recent period were as follows: total bilirubin $\leq 3 \mathrm{mg} / \mathrm{dL}$ at $20(80 \%)$ of 25 centers; prothrombin time $\geq 50 \%$ at 13 (52\%) centers; platelet count $\geq 5 \times 10^{4} / \mathrm{mm}^{3}$ at 19 (76\%) centers; absence of ascites after medication at $15(60 \%)$ centers; and Child-Pugh score $\leq 9$ at $12(48 \%)$ centers. Additionally, there were no differences in the hepatic function criteria between high-volume and low-volume RFA centers. There were no differences in total bilirubin, prothrombin time, platelet count, and the degree of ascites; however, a shift in the Child-Pugh score from $\leq 8$ to $\leq 9$ was noted during the recent period compared to the previous period. According to major guidelines, RFA is recommended for patients with HCC lesions with a Child-Pugh score of A or B [22-24]. However, 7 centers (28\%) accepted a Child-Pugh score of C during the recent period. Hiraoka et al. [26] reported that interventional radiology including RFA for HCC may prolong the survival of naive HCC patients with a Child-Pugh score of $C$ with up to 7 criteria and total bilirubin $<3 \mathrm{mg} / \mathrm{dL}$. Therefore, such patients with a Child-Pugh score of $C$ could be candidates for RFA.

According to quality improvement guidelines for RFA of liver tumors, RFA is contraindicated for the treatment of liver tumors located $<1 \mathrm{~cm}$ from the main biliary duct and a bilioenteric anastomosis [20]. The indications for RFA for patients with HCC adjacent to the first or second branch of the bile duct have increased from 15 of 20 centers (75\%) during the previous period to 21 of 25 centers (84\%) during the recent period; they have also increased for patients with a bilioenteric anastomosis or papillary dysfunction from 5 of 20 centers (25\%) during the previous period to 10 of 25 centers (40\%) during the recent period, which has consequently increased the use of bile duct cooling via nasobiliary drainage tube from 25 to $32 \%$ (Table 1). Additionally, only 13 centers (52\%) used the general criteria for tumor number and size during the recent period [20,22-24]. Therefore, our findings indicated that the criteria for RFA in terms of both patient and tumor characteristics have recently expanded. Although a statistical analysis could not be performed because these data were obtained from a questionnaire, the findings are beneficial for clinical practice.

Shiina et al. [11] reported that the mortality and complication rates were 0.03 and $1.5 \%$, respectively, during an analysis of 2,982 RFA procedures for 1,170 patients with HCC at a single high-volume center where the largest number of RFA treatments was performed. The complication rate for RFA has been reported by multiple centers in a few studies $[4,6,8,12]$, and systematic reviews have reported RFA-related mortality and complication rates $[13,14]$. In 2002, Mulier et al. [13] reported a mortality rate of $0.5 \%$ and a complication rate of $8.9 \%$ among 3,670 cases of RFA, with lower rates of 0.16 and $4.1 \%$, respectively, reported by Bertot et al. [14] for 9,531 cases in 2011. A Japanese national survey performed in 2012 reported mortality and complication rates of 0.25 and $4.54 \%$, respectively, for 11,688 cases [25]. We also reported a mortality rate of $0.038 \%$ and a complication rate of $3.54 \%$ for 13,283 cases in 2012 [15]. During the recent period, the mortality and complication rates were 0.064 and $2.92 \%$, respectively. Although the mortality rate was not significantly different between the recent (2011-2015) and previous (1999-2010) periods ( $p=0.38)$, the complication rate was significantly lower during the recent period than during the previous period $(p=0.038)$, despite the expansion of the criteria for RFA during the recent period. This recent improvement in the RFA-associated complication rate likely resulted from the increased use of several modifications to RFA (Fig. 3), as well as from the increased reliance on image-guidance modalities that were used for 5,294 of 11,298 procedures (46.9\%; Fig. 5). Therefore, precise targeting with these modalities could result in lower complication rates.

In this study, we used the same classifications of the following 6 categories of complications reported in our previous study [15]: hemorrhage, hepatic injuries, extrahepatic organ injuries, tumor progression, skin burn due to poor contact between the electrode pad and the skin, and others (Table 1). Compared to the complication rates during the previous period (1999-2010), the complication rates for hepatic injuries, tumor progression, and skin burn 
were significantly lower during the recent period than during the previous period. However, for the category of extrahepatic organ injuries, the complication rate of pneumothorax markedly increased during the recent period $(0.424 \%)$ compared to the previous period $(0.055 \%)$, with 37 of these 48 cases $(77.1 \%)$ occurring at one center. This center performed RFA under CT guidance in 106 cases in the recent period of observation, for HCCs located in the hepatic dome, which requires a transpulmonary approach that is a high-risk factor for pneumothorax [27]. As such, most cases of pneumothorax in this study were considered predictable complications of the transpulmonary approach.

In Japan, with the recent decrease in the incidence of liver tumors, which are almost all HCC lesions [28], there has been a gradual decline in the number of RFA procedures performed during the recent 5-year period of observation (Fig. 4). Additionally, the incidence of HCC with non-viral etiologies (NBNC-HCC) has recently increased in Japan [29]. HCC tends to be diagnosed at an advanced stage because of the lack of adequate surveillance for NBNC-HCC [30], which has also caused a decrease in the number of RFA procedures. Moreover, although the Cool-tip Radiofrequency System was predominantly (87.94\%) used during the early part of the observation period, the use of this system significantly decreased with the introduction of new RFA devices, including the Celon-POWER System and VIVARF System. Although the complication rates for the different RFA systems cannot be simply compared due to various biases, the incidence of complications remained low for the Cool-tip and RTC Systems (at approximately 3\%) because of the accumulated experience using these RFA devices. The complication rate was also low for the VIVARF System, which uses an electrode with the same shape as that of the Cool-tip System. However, the complication rates associated with the Celon-POWER System were $6.76 \%$ in 2013, 7.30\% in 2014, and $2.86 \%$ in 2015, respectively. In Japan, the Celon-POWER System was introduced in 2013. We considered that the complication rates during the first 2 years was high because physicians had no experience with this system; however, its complication rate was markedly reduced in 2015 because of the accumulated experience using this system. The complication rate in 2015 was similar to that previously reported (2.7\%) [31]. Another report demonstrated that the major complication rate was equal to that of multipolar RFA and monopolar RFA at $7.2 \%$, with no significant difference [17]. In our study, specifically when comparing complications associated with the Celon-POWER System and the Cool-tip System, the complication rates of extrahepatic injuries were significantly higher for the Celon-POWER than for the Cool-tip system (online suppl. Table). Therefore, it is suggested that appropriate insertion of multiple electrodes around the liver tumor is very difficult, even for expert physicians. When multipolar RFA is performed under ultrasound guidance, considerable skills are required to understand the position relation of multiple electrodes. Since 2014, a new simulator system, the 3D sim-Navigator [32, $33]$, has been used at 3 centers ( 95 procedures) and could facilitate the safe insertion of multiple electrodes around the tumor. The 3D sim-Navigator may also contribute to reduced complications associated with the Celon-POWER System.

The limitations of our study should be acknowledged. First, some important clinical data that may affect the mortality and complication rates associated with RFA, such as the size and location of the tumor, liver reserve capacity (e.g., Child-Pugh), and coexisting disease (e.g., diabetes, renal failure, heart disease, etc.), were not included in the questionnaires used for data collection. Second, although we compared the findings during 2 observation periods (1999-2010 and 2011-2015), we did not consider differences in patients' backgrounds and physicians' skills. However, our study had the distinct advantage of providing outcomes of a large-scale population of more than 20,000 patients and was the first to compare mortality and complication rates of different periods.

In conclusion, this study confirmed that RFA, including RFA using new devices, is a low-risk procedure for HCC, despite the expansion of the criteria for RFA during the recent 
Maeda et al.: Complications after RFA for HCC

period. Additionally, the use of several modifications and image-guidance modalities for the RFA procedure could possibly decrease the complication rates.

\section{Statement of Ethics}

This study was conducted in compliance with the ethical principles of the Declaration of Helsinki. The protocol (H29-071) was approved by the IRB of Yamaguchi University Hospital.

\section{Disclosure Statement}

I. Sakaida: received funding from Otsuka and Gilead; K. Takaguchi: received funding from AbbVie KK, MSD, Bristol Myers Squibb, AstraZeneca KK, and Gilead; the other authors do not have any disclosures.

\section{Funding Sources}

No financial support was received for this study.

\section{Author Contributions}

M. Maeda, I. Saeki, and T. Yamasaki designed the study, analyzed the data, and wrote the paper. M. Maeda, I. Saeki, I. Sakaida, H. Aikata, Y. Araki, C. Ogawa, K. Kariyama, K. Nouso, M. Kitamoto, H. Kobashi, S. Sato, H. Shibata, K. Joko, S. Takaki, H. Takabatake, A. Tsutsui, K. Takaguchi, T. Tomonari, S. Nakamura, T. Nagahara, A. Hiraoka, T. Matono, M. Koda, M. Mandai, T. Mannami, A. Mitsuda, T. Moriya, K. Yabushita, J. Tani, and T. Yagi collected data and/or responded to a questionnaire. M. Maeda and I. Saeki performed the statistical analysis. K. Nouso, H. Takagushi, and M. Koda revised the manuscript for important intellectual content.

\section{References}

1 GLOBOCAN. 2018. Available from: http://globocan.iarc.fr/.

2 Kudo M. Surveillance, diagnosis, treatment, and outcome of liver cancer in Japan. Liver Cancer. 2015 Mar;4(1): 39-50.

3 Kudo M, Izumi N, Ichida T, Ku Y, Kokudo N, Sakamoto M, et al. Report of the 19th follow-up survey of primary liver cancer in Japan. Hepatol Res. 2016 Mar;46(5):372-90.

4 Livraghi T, Solbiati L, Meloni MF, Gazelle GS, Halpern EF, Goldberg SN. Treatment of focal liver tumors with percutaneous radio-frequency ablation: complications encountered in a multicenter study. Radiology. 2003 Feb;226(2):441-51.

5 de Baère T, Risse 0 , Kuoch V, Dromain C, Sengel C, Smayra T, et al. Adverse events during radiofrequency treatment of 582 hepatic tumors. AJR Am J Roentgenol. 2003 Sep;181(3):695-700.

6 Rhim H, Yoon KH, Lee JM, Cho Y, Cho JS, Kim SH, et al. Major complications after radio-frequency thermal ablation of hepatic tumors: spectrum of imaging findings. Radiographics. 2003 Jan-Feb;23(1):123-34.

7 Buscarini E, Buscarini L. Radiofrequency thermal ablation with expandable needle of focal liver malignancies: complication report. Eur Radiol. 2004 Jan;14(1):31-7.

8 Kasugai H, Osaki Y, Oka H, Kudo M, Seki T; Osaka Liver Cancer Study Group. Severe complications of radiofrequency ablation therapy for hepatocellular carcinoma: an analysis of 3,891 ablations in 2,614 patients. Oncology. 2007;72 Suppl 1:72-5.

9 Chen TM, Huang PT, Lin LF, Tung JN. Major complications of ultrasound-guided percutaneous radiofrequency ablations for liver malignancies: single center experience. J Gastroenterol Hepatol. 2008 Aug;23(8 Pt 2):e44550.

10 Kong WT, Zhang WW, Qiu YD, Zhou T, Qiu JL, Zhang W, et al. Major complications after radiofrequency ablation for liver tumors: analysis of 255 patients. World J Gastroenterol. 2009 Jun;15(21):2651-6.

11 Shiina S, Tateishi R, Arano T, Uchino K, Enooku K, Nakagawa H, et al. Radiofrequency ablation for hepatocellular carcinoma: 10-year outcome and prognostic factors. Am J Gastroenterol. 2012 Apr;107(4):569-77.

12 Ding J, Jing X, Liu J, Wang Y, Wang F, Wang Y, et al. Complications of thermal ablation of hepatic tumours: comparison of radiofrequency and microwave ablative techniques. Clin Radiol. 2013 Jun;68(6):608-15. 
13 Mulier S, Mulier P, Ni Y, Miao Y, Dupas B, Marchal G, et al. Complications of radiofrequency coagulation of liver tumours. Br J Surg. 2002 Oct;89(10):1206-22.

14 Bertot LC, Sato M, Tateishi R, Yoshida H, Koike K. Mortality and complication rates of percutaneous ablative techniques for the treatment of liver tumors: a systematic review. Eur Radiol. 2011 Dec;21(12):2584-96.

15 Koda M, Murawaki Y, Hirooka Y, Kitamoto M, Ono M, Sakaeda H, et al. Complications of radiofrequency ablation for hepatocellular carcinoma in a multicenter study: an analysis of 16346 treated nodules in 13283 patients. Hepatol Res. 2012 Nov;42(11):1058-64.

16 Osaki Y, Ikeda K, Izumi N, Yamashita S, Kumada H, Hatta S, et al. Clinical effectiveness of bipolar radiofrequency ablation for small liver cancers. J Gastroenterol. 2013 Jul;48(7):874-83.

17 Hocquelet A, Aubé C, Rode A, Cartier V, Sutter O, Manichon AF, et al. Comparison of no-touch multi-bipolar vs. monopolar radiofrequency ablation for small HCC. J Hepatol. 2017 Jan;66(1):67-74.

18 Lee MW, Rhim H, Cha DI, Kim YJ, Choi D, Kim YS, et al. Percutaneous radiofrequency ablation of hepatocellular carcinoma: fusion imaging guidance for management of lesions with poor conspicuity at conventional sonography. AJR Am J Roentgenol. 2012 Jun;198(6):1438-44.

19 Kim YS, Lim HK, Rhim H, Lee MW. Ablation of hepatocellular carcinoma. Best Pract Res Clin Gastroenterol. 2014 Oct;28(5):897-908.

20 Crocetti L, de Baere T, Lencioni R. Quality improvement guidelines for radiofrequency ablation of liver tumours. Cardiovasc Intervent Radiol. 2010 Feb;33(1):11-7.

21 Ahmed M, Solbiati L, Brace CL, Breen DJ, Callstrom MR, Charboneau JW, et al.; International Working Group on Image-guided Tumor Ablation; Interventional Oncology Sans Frontières Expert Panel; Technology Assessment Committee of the Society of Interventional Radiology; Standard of Practice Committee of the Cardiovascular and Interventional Radiological Society of Europe. Image-guided tumor ablation: standardization of terminology and reporting criteria-a 10-year update. Radiology. 2014 0ct;273(1):241-60.

22 Kudo M, Matsui O, Izumi N, Iijima H, Kadoya M, Imai Y, et al.; Liver Cancer Study Group of Japan. JSH consensusbased clinical practice guidelines for the management of hepatocellular carcinoma: 2014 update by the Liver Cancer Study Group of Japan. Liver Cancer. 2014 Oct;3(3-4):458-68.

23 Omata M, Cheng AL, Kokudo N, Kudo M, Lee JM, Jia J, et al. Asia-Pacific clinical practice guidelines on the management of hepatocellular carcinoma: a 2017 update. Hepatol Int. 2017 Jul;11(4):317-70.

24 Bruix J, Sherman M; American Association for the Study of Liver Diseases. Management of hepatocellular carcinoma: an update. Hepatology. 2011 Mar;53(3):1020-2.

25 Sato M, Tateishi R, Yasunaga H, Horiguchi H, Yoshida H, Matsuda S, et al. Mortality and morbidity of hepatectomy, radiofrequency ablation, and embolization for hepatocellular carcinoma: a national survey of 54,145 patients. J Gastroenterol. 2012 Oct;47(10):1125-33.

26 Hiraoka A, Kumada T, Michitaka K, Toyoda H, Tada T, Ishikawa T, et al.; Hiroaki Nagamatsu, on behalf of the Real-life Practice Experts for HCC (RELPEC) Study Group. Is there a survival benefit in interventional radiology for hepatocellular carcinoma in patients with Child-Pugh C liver cirrhosis?: A multicenter study. Hepatol Res. 2016 May;46(6):521-8.

27 Toyoda M, Kakizaki S, Horiuchi K, Katakai K, Sohara N, Sato K, et al. Computed tomography-guided transpulmonary radiofrequency ablation for hepatocellular carcinoma located in hepatic dome. World J Gastroenterol. 2006 Jan;12(4):608-11.

28 Center for Cancer Control and Information Services, National Cancer Center, Japan. Available from: https:// ganjoho.jp/en/index.html.

29 Tateishi R, Uchino K, Fujiwara N, Takehara T, Okanoue T, Seike M, et al. A nationwide survey on non-B, non-C hepatocellular carcinoma in Japan: 2011-2015 update. J Gastroenterol. 2019 Apr; 54(4):367-76.

30 Utsunomiya T, Shimada M, Kudo M, Ichida T, Matsui O, Izumi N, et al.; Liver Cancer Study Group of Japan. A comparison of the surgical outcomes among patients with HBV-positive, HCV-positive, and non-B non-C hepatocellular carcinoma: a nationwide study of 11,950 patients. Ann Surg. 2015 Mar;261(3):513-20.

31 Seror 0, N'Kontchou G, Nault JC, Rabahi Y, Nahon P, Ganne-Carrié N, et al. Hepatocellular carcinoma within Milan Criteria: no-touch multibipolar radiofrequency ablation for Treatment-Long-term results. Radiology. 2016 Aug;280(2):611-21.

32 Hirooka M, Koizumi Y, Imai Y, Miyake T, Watanabe T, Yoshida O, et al. Usefulness of a new three-dimensional simulator system for radiofrequency ablation. PLoS One. 2016 Feb;11(2):e0148298.

33 Hirooka M, Koizumi Y, Imai Y, Nakamura Y, Yukimoto A, Watanabe T, et al. Clinical utility of multipolar ablation with a 3-D simulator system for patients with liver cancer. J Gastroenterol Hepatol. 2017 Nov;32(11):1852-8. 